\title{
UNIVERSITYOF
}

FORWARD

THINKING

WESTMINSTER用

WestminsterResearch

http://www.westminster.ac.uk/westminsterresearch

Using qualitative diary research to understand emotion at work Waddington, $\mathrm{K}$.

This is a pre-publication version of a book chapter published in: Bakker, A.B. and Daniels, K. (eds.) A Day in the Life of a Happy Worker, Psychology Press, pp. 132-149.

The WestminsterResearch online digital archive at the University of Westminster aims to make the research output of the University available to a wider audience. Copyright and Moral Rights remain with the authors and/or copyright owners.

Whilst further distribution of specific materials from within this archive is forbidden, you may freely distribute the URL of WestminsterResearch: ((http://westminsterresearch.wmin.ac.uk/)).

In case of abuse or copyright appearing without permission e-mail repository@westminster.ac.uk 
Waddington, K. (2013) 'Using qualitative diary research to understand emotion at work'. Chapter 10 in A. B. Bakker and K. Daniels (eds) A Day in the Life of a Happy Worker. Hove: Psychology Press.

\section{Using Qualitative Diary Research to Understand Emotion at Work}

\section{Kathryn Waddington}

My work is like a diary. To understand it you have to see how it mirrors life.

Pablo Picasso (1881-1973)

This chapter addresses the role of qualitative diary research as a method for documenting subjective experiences and emotions at work. Qualitative diary research can yield rich insights into relationships, processes, events and settings and diaries more generally are a means by which to "capture the particulars of experience in a way that is not possible using traditional designs' (Bolger, Davis \& Rafaeli, 2003, p. 579). The chapter addresses issues relating to the strengths, limitations, ethical considerations, design and conduct of qualitative diary research. Researchers are not immune to emotion in and about their work, and the role and use of diaries in reflexive research practice are also discussed using extracts from three researchers' diaries/field notes as illustrative examples. Empirical data from multimethod organizational psychology research into work-related gossip are also included as practical examples of using diary research methods and working reflexively (Waddington, 2005; 2010a; Waddington \& Fletcher, 2005). The broad aim of the chapter is to outline and discuss ways of conducting qualitative diary research on emotions in the workplace and illustrate how such qualitative data can be analyzed.

\section{THE DEVELOPMENT OF DIARY RESEARCH}

Diaries are a familiar feature of everyday life, used to record social engagements as well as activities and events, thoughts and feelings. Commentators and politicians from Samuel Pepys's time onwards have written diaries as a memoir for posterity through archives and 
Waddington, K. (2013) 'Using qualitative diary research to understand emotion at work'. Chapter 10 in A. B. Bakker and K. Daniels (eds) A Day in the Life of a Happy Worker. Hove: Psychology Press.

more recently profit through publication. Mullin (2010) suggests that 'the most successful political diarists are people who have occupied the lower foothills... because they have had time to look around and observe details' (p. 2). Diaries are used in qualitative research for precisely the same reasons, to observe and document the details of everyday experience. Researcher-led diaries, often referred to as solicited diaries, can be used to collect both qualitative and quantitative data, transforming private, subjective intrapersonal processes into public data open to scrutiny and interpretation.

Allport's The Use of Personal Documents in Psychological Science is frequently cited as one of the earliest discussions on the use of diaries as a research tool. For Allport, familiarity with the 'particulars of life' is the foundation of all psychological knowledge: 'Psychology needs to concern itself with life as it is lived, with significant total-processes of the sort revealed in consecutive and complete life documents' (Allport, 1942, p. 56; cited in Bolger at al., 2003, p. 580). Diaries have been used in research in a broad range of areas including occupational stress, personal identity, text messaging, organizational culture and change, and patients' reactions to the diagnosis and experience of serious illness (e.g., Clarkson \& Hodgkinson, 2007; Patterson, 2005; Plowman, 2010; Willig, 2009). Diaries can vary enormously in terms of structure and flexibility in the ways in which information is captured and recorded, for example using an electronic personal digital assistant (PDA), audio diary recording, and paper-and-pencil records. Alaszewski's (2006) analysis of the role of diaries in social research notes their use in a wide range of different research designs including experimental, social survey, historical, ethnographic and naturalistic research. 
Waddington, K. (2013) 'Using qualitative diary research to understand emotion at work'. Chapter 10 in A. B. Bakker and K. Daniels (eds) A Day in the Life of a Happy Worker. Hove: Psychology Press.

Diaries are particularly suited to naturalistic research as they enable the collection of 'realtime' data, recorded as subjective experiences occurring in their natural, spontaneous context. Used in this manner, diaries can access and reveal taken-for-granted activities and insights into how individuals ascribe meanings to actions and social interactions. Qualitative diaries can elicit rich emotional data, as illustrated in Box 1 below, written by Carla Willig (2009), about her experience of being diagnosed and treated for cancer.

Insert Box 1 about here

This is a powerful example of qualitative diary data which reveals, in this instance, strong emotions and insight into subjective cognitive experiences.

Plowman's (2010) 'diary project' used qualitative diaries, participant dialogue and interviews in an investigation into gendered organization, power and change in a South African non-governmental organization. The diary project revealed aspects of organizational life that would have otherwise remained hidden and silenced. Plowman's study is noteworthy for two reasons. Firstly, it illustrates a potentially significant role for qualitative diary designs in linking subjective experience with organizational processes, and the interface between the informal and formal, personal and professional/organizational practices. Secondly, the methodology, which allows for intervention as well as study, is highly relevant to researchers interested in designing and evaluating employee engagement because:

The diary project methodology is also experienced as being both useful and energising. In the process of bringing staff together across formal and informal hierarchies and divisions, the diary project creates space for shared reflection and 
Waddington, K. (2013) 'Using qualitative diary research to understand emotion at work'. Chapter 10 in A. B. Bakker and K. Daniels (eds) A Day in the Life of a Happy Worker. Hove: Psychology Press.

ideas for change. The methodology as an intervention also gives opportunity for thinking about and taking steps to build inclusive organisational cultures.

(Plowman, 2010; p. 44, emphasis added)

While qualitative research in work and organizational psychology is gaining ground (Cassell \& Symon, 2006; Lee, Mitchell \& Harman, 2011), diary studies in this field have tended to favour a more quantitative approach in order to answer questions regarding 'aggregates of experiences over time, temporal patterns of experiences, and the factors affecting changes in these experiences' (Bolger et al., 2003; p. 588). It is beyond the remit of this chapter to discuss quantitative diary methods in detail, however later in the chapter a multimethod research study into work-related gossip (Waddington, 2005) is discussed as an illustrative example of analysis and integration of qualitative and quantitative diary data. Diaries as a research method have evident utility in psychological inquiry in quantitative, qualitative and what has been variously, and sometimes interchangeably, termed third paradigm, multimethod, multi-strategy and mixed methods research (Teddlie \& Tashakkorie, 2009).

\section{Strengths and limitations of qualitative diaries}

Diaries are useful incapturing subjective responses to events in real-time, and are a means of uncovering and digging deep into everyday processes and events which may otherwise be neglected, hidden or silenced. The quality and quantity of data is likely to be different to that available through questionnaire or retrospective interviews and can provide a more comprehensive and nuanced picture. Data based on human experience, as we have seen, are powerful and more compelling than quantitative data alone, and diaries can also be designed to collect quantitative and qualitative data at the same time. They can capture events close to when they unfold with the potential to trace events over time, providing a record of ever 
Waddington, K. (2013) 'Using qualitative diary research to understand emotion at work'. Chapter 10 in A. B. Bakker and K. Daniels (eds) A Day in the Life of a Happy Worker. Hove: Psychology Press.

changing individual and organizational landscapes. Diaries allow researchers to track contemporaneous public and private events, require relatively little of the researcher's time and, in paper-and-pencil form, are relatively cheap to administer. According to Bolger et al. (2003) electronic diaries such as Personal Digital Assistants (PDAs) have advantages for the conduct of diary studies such as their ability to allow for signalling and the provision of time stamps. However there are some disadvantages associated with PDAs and electronic diaries primarily relating to cost, maintenance and training participants in how to use them.

Other limitations of qualitative diaries more generally are that researchers are reliant upon diarists' conscientiousness, honesty, self-awareness and insight. Knowledge that diaries will be read, analyzed, and interpreted may result in diarists' censoring entries to avoid embarrassment, although self-consciousness tends to decrease over time (Milligan, Bingley \& Gatrell, 2005). However studies that require participation over a long period of time may also result in high attrition or less complete or accurate data towards the end, requiring gentle reminders in the form of visits, telephone calls, texts or emails from the researcher.

\section{DESIGNING QUALITATIVE DIARY RESEARCH}

When designing qualitative diary research it is important to recognise that the approach is deliberately open and flexible. A variety of free response techniques can be used to enable participants to recall and record personally meaningful events and interactions which have emotional resonance. For example, qualitative diaries can also be used in a number of different ways including descriptive experience sampling, audio diaries, recording of critical incidents, and creative reflective journals (Chell, 2004; Clarkson \& Hodgkinson, 2007; Duncan, 2004; Heavey, Hurlburt \& Lefforge, 2010; Theodosius, 2006). Because of this 
Waddington, K. (2013) 'Using qualitative diary research to understand emotion at work'. Chapter 10 in A. B. Bakker and K. Daniels (eds) A Day in the Life of a Happy Worker. Hove: Psychology Press.

diversity there are no specific typologies or standardized approaches to follow, therefore a recap of the principles of rigorous and ethical research practice is given as a starting point.

The principles outlined here are drawn from the criteria used by the Journal of Occupational and Organizational Psychology to evaluate papers using qualitative methods (http://www.bpsjournals.co.uk/journals/joop/qualitative-guidelines.cfm, accessed $17^{\text {th }}$ November 2010). Ethical issues are important yet they are frequently neglected, or simply implied, in guidance for the design and practice of diary research. For example, Bolger et al.'s (2003) frequently cited review of diary methods makes no mention of ethical issues at all. Symon (2004) on the other hand does acknowledge the need to assure respondents of the confidentiality of completed diary records and the importance of ensuring anonymity in the reporting of findings, but there is little detailed discussion. Clearly, researchers are required to work within ethical codes of practice, and research proposals receive ethical scrutiny by funding bodies and committees. These are the professional and procedural ethical considerations, but there is also another dimension of 'ethics in practice' (Guillemin \& Gillam, 2004).

\section{Ethics in practice}

Diaries written for personal use are private documents, solicited diaries written for research purposes are public documents, and the rights and privacy of 'absent' third parties, for example individuals or organizations who may appear in a diary record, need to be acknowledged and protected. Furthermore, research participants may reveal information about illegal activities, moral judgements or gossip about other people or organizations. Researchers' own diaries may be used to reflect on ethical dilemmas raised by information 
Waddington, K. (2013) 'Using qualitative diary research to understand emotion at work'. Chapter 10 in A. B. Bakker and K. Daniels (eds) A Day in the Life of a Happy Worker. Hove: Psychology Press.

given during their research and the following questions can be used to aid 'ethical

reflexivity'. Consider for example: (i) how are you going to act ethically?; (ii) are any

adjustments required by you or your research design in order to be sensitive to participants or third parties?; (iii) if a research diary record was inadvertently found what might be the outcome?

Diary data, like all research data, must be confidential and secure, and participants and researchers need to give careful consideration to storage and accessibility, particularly in the field site and in transit (e.g., data used/stored on laptops and USB storage devices). In the, albeit unlikely, event that an individual or organization taking part in a research study is involved in litigation, diary data may be subject to disclosure. For example in the U.K. under Rule 31 of the Civil Procedure Rules, any record of information may be required to be disclosed (http://www.justice.gov.uk/civil/procrules_fin/contents/parts/part31.htm, accessed $17^{\text {th }}$ November 2010). This extends from hand written notes, letters and correspondence through emails to computer discs, photographs and any other way of permanently recording information. Researchers also need to ensure their practice is compliant with relevant legislation regarding data protection, and give accurate information to participants regarding how any personal information will be stored and used.

\section{Principles of qualitative diary research design}

These relate to overarching principles of good research design, with a clearly stated rationale for using qualitative diaries and how this is justified in terms of the research question. There should be congruence between method and psychological/interdisciplinary theoretical perspectives and a clearly articulated and consistent epistemological approach. Qualitative diaries are likely to involve either 
Waddington, K. (2013) 'Using qualitative diary research to understand emotion at work'. Chapter 10 in A. B. Bakker and K. Daniels (eds) A Day in the Life of a Happy Worker. Hove: Psychology Press.

paper-and-pencil or digital media methods of data collection, and sampling decisions may need to take account of participants' IT skills, literacy, self awareness, insight and any training needs for instance in using digital media recording devices or PDAs. Ethically, participants will need to know: (i) how the information they provide will be used, and give consent for their data to be used in reports and publications; (ii) realistic estimations of how much of their time will be taken up completing diaries; (iii) how to contact the researcher and what to do should they have concerns about the conduct of the study; and (iv) what support is available should any aspect of participation cause distress.

Qualitative diary records may be unstructured, or lightly structured, but all will need to have clear and unambiguous instructions for completion, and pilot studies can yield useful feedback here. The instructions used to guide, rather than prescribe, diary entries will clearly depend upon the research question. Face-to-face introductory briefing sessions, either individually or in groups are crucial to establish rapport and trust, and to clarify the practical requirements of diary keeping. They also provide an opportunity to raise concerns about the overall conduct of the study or any specific ethical concerns (Plowman, 2010). Qualitative interviews may also be incorporated into the design after the completion of diaries to clarify meaning and understanding as well as probe further to elicit deeper insights. Additional qualitative data should be also collected by researchers in the form of detailed field notes of observations, emotions, insights as well as a research diary to aid their reflexive research practice (Nadin \& Cassell, 2006).

\section{Data analysis}


Waddington, K. (2013) 'Using qualitative diary research to understand emotion at work'. Chapter 10 in A. B. Bakker and K. Daniels (eds) A Day in the Life of a Happy Worker. Hove: Psychology Press.

Qualitative data analysis is fundamentally an iterative process which may, to a lesser or greater extent, be guided by the methodological approach adopted, for example grounded theory or interpretive phenomenological analysis (Willig \& Stainton-Rogers, 2008). Iteration is not a repetitive mechanical task, rather it is a reflexive process which involves: 'visiting and revisiting the data and connecting them with emerging insights, progressively leading to refined focus and understandings' (Srivastava \& Hopwood, 2009; p. 77). An overarching principle is the requirement for a clear rationale and articulation of an analytic framework/approach, accurate and complete descriptions of analytic procedures, processes and audit trail. If more than one source and/or type of data are collected, the framework should also include the process/es for combining and integrating data and findings. The development and use of such a framework is described next in an illustrative research example of the practical use of diary methods.

\section{USING DIARIES TO STUDY WORK-RELATED GOSSIP}

This section summarises key aspects of a multimethod doctoral research study into workrelated gossip which used quantitative and qualitative diary methods in the final phase. The focus here is predominantly upon methodological issues, but for further details see (Waddington, 2005).

\section{Research design}

The overall research design combined qualitative and quantitative methods of data collection, analysis and inference across three phases. This approach was a product of the "pragmatist paradigm', rejecting the incommensurate paradigm view of qualitative and quantitative research, and the 'either/or' choice between methods (see Teddlie \& Tashakkorie, 2009). The 
Waddington, K. (2013) 'Using qualitative diary research to understand emotion at work'. Chapter 10 in A. B. Bakker and K. Daniels (eds) A Day in the Life of a Happy Worker. Hove: Psychology Press.

diary study built upon findings from two earlier phases which had used repertory grids, a twenty statements method, critical incident analysis and in-depth qualitative interviews (for details see Waddington \& Fletcher, 2005). The aim was to examine further the emotions expressed in gossip, the nature of the gossiper-gossipee interpersonal relationships, and wider organizational factors. A variant of the Rochester Interaction Record (RIR, Reis \& Wheeler, 1991) was used to record incidents of gossip, the emotions associated with the incidents and other aspects of the interaction, as illustrated in Figure 1.

Insert Figure 1 about here

Sample: A convenience sample of 20 was chosen because in qualitative research sample sizes tend to be smaller. However it was also envisaged that data generated from the structured diary records would enable quantification of aspects of gossip at the event level. Participants were all experienced nurses working in a variety of clinical, managerial and educational roles in South East England.

Ethical considerations: The instructions to participants were carefully worded - see Figure 1 to avoid inappropriate disclosure of names/identities or organizations. This is a moral imperative when collecting gossip related data, particularly if it is negative, judgmental, or distorts and trivializes the experience of others.

Data collection: Instructions to participants and dairy record sheets were given out at a briefing meeting. Gossip is notoriously difficult to define (see Michelson, van Iterson \& Waddington, 2010); in this study, the following 'attributes of gossip', drawn from the literature were used to determine what constituted a 'gossip event': (i) gossip is informal talk; 
Waddington, K. (2013) 'Using qualitative diary research to understand emotion at work'. Chapter 10 in A. B. Bakker and K. Daniels (eds) A Day in the Life of a Happy Worker. Hove: Psychology Press.

(ii) occurring between small groups of 2 or more people; (iii) which concerns the verbal exchange of information; (iv) about work related issues. Participants were not necessarily able to stop and record incidents immediately after the event, and were instructed to do this as soon as possible, and at least once a day. Semi-structured follow up telephone interviews were used to: (i) seek feedback on the 'attributes of gossip' as a means of checking their validity; (ii) ascertain accuracy of the diary records; (iii) gain more in-depth qualitative data regarding the critical incidents.

\section{Analyzing qualitative and quantitative data}

Quantitative and qualitative data were analysed on two levels using quasi-statistical, template and immersion/crystallization styles of analysis as outlined in the framework in Figure 2.

\section{Insert Figure 2 about here}

Quasi-statistical analysis was used in the first level of analysis; template analysis was used in both first and second levels of analysis, and the template developed, for example by extending or deleting codes, as data were analysed and integrated. Immersion/crystallisation and second level analysis were, in practice, an iterative cycle rather than a linear relationship. Quantitative analysis revealed that the incidents of gossip were perceived as being more pleasant than unpleasant (mean 4.74; SD 1.03; where 1= unpleasant; 7= very pleasant) and were associated with feelings of group membership and inclusion. Participants also recorded that they disclosed slightly less than the others involved in the incidents, and were less likely to have initiated the interaction, suggesting potential for attribution error and social desirability bias. This was reflected in a discrepancy in the template analysis of the qualitative data, where self-reported emotions were equally distributed across negative and 
Waddington, K. (2013) 'Using qualitative diary research to understand emotion at work'. Chapter 10 in A. B. Bakker and K. Daniels (eds) A Day in the Life of a Happy Worker. Hove: Psychology Press.

positive emotions. Another anomaly in the data suggestive of social desirability bias was that out of 273 incidents only one had: 'keeping this diary!' as a topic of gossip. However as gossip is also often about an absent third party, this anomaly is not entirely unexpected in a solicited 'public' diary where the researcher, although physically absent at the time of recording, is present as a reader, analyst and interpreter.

Figure 3 provides an extract from the diary study coding template relating to emotional expression and outcome.

Insert Figure 3 about here

The template defined higher order codes that were both theory and data driven, arising from the literature review and preliminary phases of the research. The template was amended by adding/combining/removing lower order codes as engagement with new data occurred and analysis progressed. There were some complex issues evident; for example engaging in gossip may either: (i) enable the expression of concern, for example about another person's health; or (ii) result in feelings of concern for the third party being gossiped about. Concern for self was expressed in terms of anxiety and worry:

'Glad to put the experience into words as it had been quite unusual and worrying.' 'I felt slightly anxious.'

Integrating quantitative and qualitative data analysis: This is represented in the second-level analysis and immersion/crystallization style in Figure 2, and was achieved by using 'vertical passes through the data' (Borkan, 1999, p. 186) to further develop and refine the coding template. For example with regard to anxiety, the underlying issues from an event/individual level of analysis relating to uncertainty and anxiety about the future was intertwined with 
Waddington, K. (2013) 'Using qualitative diary research to understand emotion at work'. Chapter 10 in A. B. Bakker and K. Daniels (eds) A Day in the Life of a Happy Worker. Hove: Psychology Press.

qualitative telephone interview data to reveal organizational issues relating to power, role and job security:

A tremendous effect [organizational uncertainty and change] - in nursing and in the public sector the pay is not good, but you do have some job security. When that gets threatened people tend to talk about the uncertainty and their anxieties about the future. There's a lot of inaccurate information about redundancies, particularly among the ancillary staff - doctors and nurses have their professional status to protect them, so I think they feel a bit more secure, ancillary staff don't have this, they get sucked into the rumours.

(Extract from telephone interview)

The data analysis task in the diary study was complex and time consuming, partly because of the volume of data generated, and also in using a coding template to analyse the qualitative data, and then developing the template further.

Implications for future research: Gossip is emerging as a topic of interdisciplinary interest in the social and organizational sciences yet to date there are still relatively few empirical studies. The value of diaries in future research into organizational gossip is evident, providing a means of capturing gossip-in-situ. As we note in van Iterson, Waddington and Michelson (forthcoming, 2011) diaries provide an excellent opportunity for longitudinal organizational culture research, while another methodological possibility includes secondary analysis of data published in political diaries.

\section{RESEARCHING EMOTION AT WORK}

Having looked at the role of diaries in a broad social research context, as well as their use in researching work-related gossip, the focus now shifts more specifically to their role in researching emotion at work. Emotion is a dynamic and multi-faceted concept, involving 
Waddington, K. (2013) 'Using qualitative diary research to understand emotion at work'. Chapter 10 in A. B. Bakker and K. Daniels (eds) A Day in the Life of a Happy Worker. Hove: Psychology Press.

transient feelings in response to a particular cause or target, cognitions, expressive behaviour and neurological and physiological changes (Grandey, 2008). There is however huge variety in the ways in which researchers have approached the definition of emotion, the most widely held and concise being 'emotions are adaptive responses to the demands of the environment' (Elfenbein, 2007; p. 316). Happiness can be understood in terms of positive emotional states such as contentment, joy and pleasure, in broader conceptual terms such as affect and wellbeing, and in relation to more negative perspectives such as anxiety, stress or dissatisfaction (Warr, 2007).

As Elfenbein (2007) notes, from a psychological perspective the field of emotion at work and in organizations has grown rapidly, and messily, over the last 20 years or so, into a popular and popularized area of inquiry and in some respects this has been problematic. For example, Briner and Keifer's $(2005 ; 2009)$ reviews of research in the field found a relatively uncritical approach to empirical studies, a lack of attention to event-based data collection methods, and other serious limitations, including poor quantification and methods that are incongruent with psychological theory of emotion. Of particular relevance to qualitative diary research is the lack of event-based methods, because: 'Without some understanding of the specific emotionprovoking event and context, and meaning of that event, we are only assessing emotion in a very partial way' (Briner and Kiefer, 2005; p. 308). The incongruence between theory and methods is also pertinent to the focus of this chapter, not least because of the extensive body of knowledge and literature which form the interdisciplinary foundations of our understanding of emotion at work (Elfenbein, 2007; Grandey, 2008; Lewis, Haviland-Jones, \& Barrett, 2008). Interdisciplinary research seeks to integrate information, data, techniques, tools, perspectives, concepts, and theories to advance understanding and solve problems 
Waddington, K. (2013) 'Using qualitative diary research to understand emotion at work'. Chapter 10 in A. B. Bakker and K. Daniels (eds) A Day in the Life of a Happy Worker. Hove: Psychology Press.

whose solutions lie beyond the scope of a single discipline or field of research practice (Calhoun \& Rhoten, 2010). Interdisciplinary approaches are important therefore in promoting coherence between theories and methods, and developing new and more comprehensive ways of assessing emotion.

Lucas and Diener (2008) point out with regard to the study of subjective well-being (SWB), some of the most exciting developments are taking place outside the traditional boundaries of psychology: 'Thus, although SWB research was initially developed within the context of existing psychology theory, it has important implications for research, theory, and application in a wide variety of domains' (p. 481). What is known about emotion is drawn from diverse disciplines including biology, genetics, health, neuroscience, anthropology, sociology, psychology, and more recently economics (Lewis et al., 2008). Development of an integrated interdisciplinary approach to research in the complex and messy field of emotion at work is pertinent, but also not unproblematic in terms of establishing linkages across disciplinary boundaries. However as Alaszewski (2006) points out, qualitative (and quantitative) diary studies have been used in a wide range of research domains and disciplines, and are one way of establishing such linkages.

Uncritical adoption of an interdisciplinary approach is as problematic as an uncritical approach to empirical studies in psychological research into emotion at work. Interdisciplinarity brings with it the risk of epistemological chaos as disciplinary ideas are disassembled and reassembled, and care is needed when working across paradigms and 
Waddington, K. (2013) 'Using qualitative diary research to understand emotion at work'. Chapter 10 in A. B. Bakker and K. Daniels (eds) A Day in the Life of a Happy Worker. Hove: Psychology Press.

perspectives (Waddington 2010b). Nevertheless, as von Scheve and von Lueve (2005; p. 305)

have pointed out:

Although the disciplines involved in emotion research scarcely present a coherent picture or unified interpretation of their data, there are certain paradigms aiming at the advancement of consistent frameworks that are capable of dealing with other disciplines' findings and also with some of the infamous pitfalls of interdisciplinary work.

They go on to advocate interfacing sociological models and theories with appraisal theories of emotion, and the incorporation of neuroscientific data into this framework in order to produce a more detailed picture of emotions as the glue holding society together. Adoption of an interdisciplinary approach brings with it opportunities to develop methodologies to address the incongruence of theory and methods and poor quantification identified by Briner and Kiefer (2009).

Interdisciplinary methodologies will, of necessity, need to transcend the boundaries of work and organizational psychology and its traditional reliance upon psychometric testing and quantitative methods. This is of course not the case across the discipline today, and qualitative methods now have a strong profile and visibility (e.g., Cassell \& Symon, 2006; Lee et al., 2011). Warr (2007) suggests that researchers and practitioners in organizations and elsewhere need to develop their thinking about happiness in the following ways: (i) consider multiple aspects; (ii) examine a wide range of environmental sources; (iii) look for non-linear patterns; (iv) explore mental processes as well as environmental features; (v) recognise the importance of personal baselines; and (vi) acknowledge that unhappiness is essential to happiness. Qualitative diary research methods which draw upon interdisciplinary perspectives 
Waddington, K. (2013) 'Using qualitative diary research to understand emotion at work'. Chapter 10 in A. B. Bakker and K. Daniels (eds) A Day in the Life of a Happy Worker. Hove: Psychology Press.

provide a means with which to consider multiple aspects of happiness, and link workplace emotion with organizational processes and outcomes. Adopting an interdisciplinary approach also provides scope for the creation of innovative research designs to achieve meaningful integration of qualitative and quantitative data.

\section{RESEARCH DIARIES AND REFLEXIVE PRACTICE}

Planned data collection in the diary study reported in this chapter was interrupted for over a year by unexpected health problems; I developed a post-viral arthritis, resulting in extremely swollen and painful joints. An unanticipated outcome (at that time) was a shift in the focus and content of my reflective research diary entries, from frustrations with the enforced interruption to a 'patient's' diary, recording my emotions and reactions to pain, immobility and chronic illness. After I recovered and re-commenced $\mathrm{PhD}$ studies I found my reflective research writing had changed and my reflexive engagement with the data had also changed; I was more mindful and reflexively aware of my cognitive and emotional responses and processes. Clearly I am not advocating that the only way to develop researcher reflexivity is to experience ill health or pain. Rather, the lesson is that researchers need to make time to be present and engaged with their data and notice the feelings which emerge.

For example, a little later when taking vertical passes through multiple data sources from all three phases of the research and 'immersed' in participants' experiences of gossip and emotion in their clinical work, I experienced a strong sense of 'academic voyeurism'. I questioned whether for me, as a nurse, doing a $\mathrm{PhD}$ was nothing more than the individual defence mechanism of intellectualisation. I felt uncomfortable, but staying with the feeling 
Waddington, K. (2013) 'Using qualitative diary research to understand emotion at work'. Chapter 10 in A. B. Bakker and K. Daniels (eds) A Day in the Life of a Happy Worker. Hove: Psychology Press.

and thinking around it helped me appreciate the value of research diaries and reflective writing as means of reflexively understanding my emotions in a research context.

Research diaries therefore are an important tool for reflexive practice, affording a deeper understanding of the role and impact of the researcher in their research encounters and endeavours, giving increased 'trustworthiness' of the data and 'integrity' in the research process (Nadin \& Cassell, 2006: 209). They create a record of reactions, thoughts, feelings insights and intuitions in relation to the research process, and can form the basis for an ongoing iterative and reflexive dialogue with self (see Waddington, 2010a).

\section{Researcher emotion}

Nicholson's (2009) psychoanalytically informed account of the importance of the researcher's emotional experience in 'practice-near' (p. 451) research with frail older people has particular resonance for qualitative researchers working with emotion in health and social care settings. The wider principles are also relevant for researchers working with emotion in other sectors and settings. Nicholson argues that the emotional experiences of the researcher as well as the participants are important data, but there is a need for an overarching theoretical framework - in her case, psychoanalytic approaches - to give validity to these emotional processes. As we have seen, emotion is a complex, messy, interdisciplinary field of inquiry and other theoretical frameworks and epistemological positions can be used to help researchers make sense of the emotions experienced in research work.

For example, Hanna Weir and I drew upon theoretical perspectives from sociology, organizational psychology and nursing in our research into recruitment and retention in health service call centres (Weir \& Waddington, 2008). In this study we were able to link and then 
Waddington, K. (2013) 'Using qualitative diary research to understand emotion at work'. Chapter 10 in A. B. Bakker and K. Daniels (eds) A Day in the Life of a Happy Worker. Hove: Psychology Press.

integrate theoretical perspectives around caring, emotion work, surveillance and control to better understand participants' emotional dissonance and feelings of disappointment and professional dissatisfaction. We have returned to our data, field notes and reflective writing to illustrate, below, how we engaged reflexively with our emotions as researchers during the data collection, analysis and reporting of the findings. This is then followed by an extract from Angie Bistakari's reflective diary as an example of a new researcher's reflections upon the emotions experienced at the beginning of her $\mathrm{PhD}$ studies.

\section{Hanna and Kathryn's reflections}

The call centre was one of a number that had been established nationally as part of a wider programme of health service reforms, and hailed as an innovative 'nurse-led service'. What we found was a service that was over-managed and under-led. Communication and information giving took place through E-mails, or not at all, which seemed incomprehensible to staff who expected more 'visible leadership'. This was in stark contrast to the tangible management practices which many felt were oppressive. Participants were very direct in their approach to 'telling it as it is':

Meeting with Joe and Fran (not their real names). For this meeting we had to go to the corridor venue again. I sensed caution in their approach and told them a bit more about my being there, and said that I wanted to get to know what people do and get the picture of the call centre, and my notes were to remind me of conversations, confidentially - so what was their job? 'It is the shittiest job here' said one looking straight at me. I was a bit surprised at such straightforward opening.

(Extract from Hanna's field notes) 
Waddington, K. (2013) 'Using qualitative diary research to understand emotion at work'. Chapter 10 in A. B. Bakker and K. Daniels (eds) A Day in the Life of a Happy Worker. Hove: Psychology Press.

As we collected, analysed and interpreted data about participants' emotion work we also reflected upon our own emotions as researchers. It became clear that for some participants being interviewed had made them reconsider their motivation for call centre work, and had precipitated a decision to leave the service. The research was having a negative impact upon staff retention - the very topic we were researching - and we felt uncomfortable about this. We also felt uncomfortable about our role as 'truth tellers', feeding back findings that were discordant with government policy, whilst retaining our integrity and authenticity as researchers. Our reflexive research conversations also revealed how some of the patterns and themes in the data interconnected with our emotional experiences of work in universities.

\section{Angie's reflections}

There are so many things to think and do and so little time. I wish I didn't have to work so much so as to have more time for my $\mathrm{PhD}$. Although I am tired and have so many things in my mind, I feel optimistic today... It's very easy now to abandon the whole $\mathrm{PhD}$. Nothing goes well. I am waiting to see what will happen in London. I wanted it so much but now I am very disappointed... Now, after a few days and having the retreat experiences [a two day event for $\mathrm{PhD}$ students and their supervisors] and some supportive meetings, I feel very good with myself and with the decisions I have made. I am very happy with the work that I am doing with my supervisors and with their support I feel that I will be able to enjoy this journey.

(Extract from Angie's reflective diary)

Angie's $\mathrm{PhD}$ journey is beginning, as it does for many students, as something of an emotional roller-coaster. Writing a reflective research diary helps us to notice and record observations 
Waddington, K. (2013) 'Using qualitative diary research to understand emotion at work'. Chapter 10 in A. B. Bakker and K. Daniels (eds) A Day in the Life of a Happy Worker. Hove: Psychology Press.

about ourselves, such as our feelings, and is a valuable way of understanding our emotional engagement with research processes and transitions.

\section{CONCLUSION}

This chapter has reflected upon the use and value of qualitative diary research in understanding the phenomenon of work-related gossip, emotion at work, and emotional aspects of researchers' work and reflexive practice. Despite acknowledgement of the emotional nature of qualitative research, there is little empirical evidence about researchers' experiences of undertaking qualitative research. I would argue that diary studies in work and organizational psychology, particularly when positioned within an interdisciplinary approach to researching emotion, have an important role for future research agendas.

\section{ACKNOWLEDGEMENTS}

I would like to thank Angie Bistakari and Hanna Weir for conversations which have contributed to this chapter, and permission to use extracts from their reflective diaries and field notes. 
Waddington, K. (2013) 'Using qualitative diary research to understand emotion at work'. Chapter 10 in A. B. Bakker and K. Daniels (eds) A Day in the Life of a Happy Worker. Hove: Psychology Press.

\section{REFERENCES}

Alaszewski, A. (2006). Using Diaries for Social Research. London, Sage.

Bolger, N., Davis, A., and Rafaeli, E. (2003). Diary methods: capturing life as it is lived. Annual Review of Psychology, 54, 579-616.

Borkan, J. (1999). Immersion/crystallization. pp. 279-294 in B. F. Crabtree and W. L. Miller (Eds.), Doing Qualitative Research $2^{\text {nd }}$ ed., Thousand Oaks, CA, Sage.

Briner, R. B. and Kiefer, T. (2005). Psychological research into the experience of emotion at work: definitely older, but are we any wiser? pp. 289-315 in N. M. Ashkanasy, C. E. J.

Härtel and W. J. Zerbe (Eds.), Research on Emotion in Organizations: The effects of affect in organizational settings (Vol. 1). Oxford, Elsevier.

Briner, R. B. and Kiefer, T. (2009). Whither psychological research into emotion at work? feeling for the future. International Journal of Work Organisation and Emotion, 3(2), 161173.

Calhoun, C. and Rhoten, D. (2009). Integrating the social sciences: Theoretical knowledge, methodological tools and practical applications. pp. 103-118 in J. Thompson Klein and C, Mitcham (Eds.) The Oxford Handbook of Interdisciplinarity, Oxford, Oxford University Press.

Cassell, C. and G. Symon (2006). Qualitative methods in industrial and organizational psychology. International Review of Industrial and Organizational Psychology, 21, 339-380. Chell, E. (2004). Critical incident technique. pp. 45-60 in C. Cassell and G. Symon (Eds.) Essential Guide to Qualitative Methods in Organizational Research, London, Sage. Clarkson, G. P. and Hodgkinson, G. P. (2007). What can occupational stress diaries achieve that questionnaires can't? Personnel Review, 36(5), 684-700.

Duncan, M. (2004). Autoethnography: Critical appreciation of an emerging art. International 
Waddington, K. (2013) 'Using qualitative diary research to understand emotion at work'. Chapter 10 in A. B. Bakker and K. Daniels (eds) A Day in the Life of a Happy Worker. Hove: Psychology Press.

Journal of Qualitative Methods, 3(4), Article 3. Retrieved from:

http://www.ualberta.ca/ iiqm/backissues/3_4/pdf/duncan.pdf (accessed 30 ${ }^{\text {th }}$ November 2010).

Elfenbein, H. A. (2007). Emotion in organizations: A review and theoretical integration. Academy of Management Annals, 1, 371-457.

Grandy, A. A. (2008). Emotions at work: a review and research agenda. pp. 235-261, in J. Barling and C. L. Cooper (Eds.), Handbook of Organizational Behavior, London, Sage. Guillemin, M. and Gillam, L. (2004). Ethics, reflexivity, and "ethically important moments" in research, Qualitative Inquiry, 10(2), 261-280.

Heavey, C. L., Hurlburt, R. T. and Lefforge, N. L. (2010). Descriptive experience sampling: a method for exploring momentary inner experience. Qualitative Research in Psychology, 7, $345-368$.

Lee, T. W., Mitchell, T. R., and Harman, W. S. (2011). Qualitative research strategies in industrial and organizational psychology. pp. 73-83 in S. Zedeck (Ed.) APA Handbook of Industrial and Organizational Psychology, Vol. 1: Building and Developing the

Organization, Washington DC: APA Association.

Lewis, M., Haviland-Jones, J. M. and Barrett, J. F. (Eds.) (2008). Handbook of Emotions $3^{\text {rd }}$ Ed. New York, The Guildford Press.

Lucas, R. E. and Diener, E. (2008). Subjective well-being. pp. 471-484 in M. Lewis, J. M. Haviland-Jones, and J. F. Barrett. (Eds.) Handbook of Emotions $3^{\text {rd }}$ Ed. New York, The Guildford Press.

Michelson, G., van Iterson, A. and Waddington, K. (2010). Gossip in organizations: contexts, consequences and controversies. Group and Organization Management, 35(4), 371-390. 
Waddington, K. (2013) 'Using qualitative diary research to understand emotion at work'. Chapter 10 in A. B. Bakker and K. Daniels (eds) A Day in the Life of a Happy Worker. Hove: Psychology Press.

Milligan, C., Bingley, A. and Gatrell, A. (2005). Digging deep: using diary techniques to explore the place of health and well-being amongst older people. Social Science and Medicine, 61(9), 1882-1892.

Mullin, C. (2010). Decline and Fall. London, Profile Books Ltd.

Nadin, S. and Cassell, C. (2006). The use of a research diary as a tool for reflexive practice: some reflections from management research. Qualitative Research in Accounting and Management, 3, 208-217.

Nicholson, C. (2009). Researcher emotions: a way into the experiences of frail older people. Journal of Social Work Practice, 23(4), 451-459.

Patterson, A. (2006). Processes, relationships, settings, products and consumers: the case for qualitative diary research. Qualitative Market Research: An International Journal, 8(2), 142156.

Plowman, P. J. (2010). The diary project: revealing the gendered organisation. Qualitative Research in Organizations and Management: An International Journal, 5(1), 28-46.

Reis, H. and Wheeler, L. (1991). Studying social interaction with the Rochester Interaction Record. Advances in Experimental Social Psychology, 24, 269-318.

Srivastava, P. and Hopwood, N. (2009). A practical iterative framework for qualitative data analysis. International Journal of Qualitative Methods, 8 (1), 76-84.

Symon, G. (2004). Qualitative research diaries. pp. 98-113 in C. Cassell and G. Symon (Eds.) Essential Guide to Qualitative Methods in Organizational Research, London, Sage.

Teddlie, C. and Tashakkorie, A. (2009). Foundations of Mixed Methods Research:

Integrating Quantitative and Qualitative Approaches in the Social and Behavioural Sciences. Los Angeles, Sage.

Theodosius, C. (2006). Recovering emotion from emotion management. Sociology, 40(5), 893-910. 
Waddington, K. (2013) 'Using qualitative diary research to understand emotion at work'. Chapter 10 in A. B. Bakker and K. Daniels (eds) A Day in the Life of a Happy Worker. Hove: Psychology Press.

van Iterson, A., Waddington, K. and Michelson G. (2011). Breaking the silence: The role of gossip in organizational culture. pp. 375-392 in N. M. Ashkanasy, C. P. M. Wilderom and M. F. Petersen (Eds.) Handbook of Organizational Culture and Climate $2^{\text {nd }}$ Ed. Thousand Oaks CA, Sage.

von Scheve, C. and von Luede, R. (2005). Emotion and social structures: Towards an interdisciplinary approach. Journal for the Theory of Social Behaviour, 35,3, 303-328. Waddington, K. (2005). Using diaries to explore the characteristics of work-related gossip: methodological considerations from exploratory, multimethod research. Journal of Occupational and Organizational Psychology, 78(2), 221-236.

Waddington, K. and Fletcher C. (2005). Gossip and emotion in nursing and health-care organisations. Journal of Health, Organisation and Management, 19(4/5), 378-394.

Waddington, K. (2010a). Organizational gossip, sense-making and the spookfish: a reflexive account. International Journal of Management Concepts and Philosophy, 4(2), 311-325. Waddington, K. (2010b). Watch this space: Working between disciplines and paradigms in the scholarship of organizational gossip, The International Journal of Interdisciplinary Social Sciences, 5, at http://www.SocialSciences-Journal.com.

Warr, P. (2007). Work, Happiness, and Unhappiness. Mahwah NJ: Erlbaum.

Weir, H. and Waddington, K. (2008). Continuities in caring? Emotion work in a NHS Direct call centre. Nursing Inquiry, 15, 1, 67-77.

Willig, C. (2009). Unlike a rock, a tree, a horse or an angel...: reflections on the struggle for meaning through writing during the process of cancer diagnosis. Journal of Health Psychology, 14(2), 181-189.

Willig, C. and Stainton Rogers, W. (2008). The SAGE Handbook of Qualitative Methods in Psychology. London, Sage. 


\section{Box 1: The Struggle for Meaning}

Source: Willig (2010; p.184, emphasis to diary entry added)

I suddenly realized (and it was a sudden insight, something which 'came to me', effortlessly and unexpected at this point) that there was only one way in which I could cope with what was happening to me, and that was to confront my mortality head-on. Later that day, I wrote the following diary entry:

I realize that the only way I can deal with this is by engaging with the experience and by confronting my mortality — and not to pretend that it isn't happening or to try to escape from it in some way. Attempts to avoid or escape from the experience only increase my anxiety and the sense of lurking horror. By contrast, the thought of embracing and fully entering this experience does not. If this is going to happen to me, I want to 'be there', and not try to be somewhere else.

I was struck by just how powerful an effect these thoughts had on my mood. The realization that I could choose to accept, to stay with, this situation rather than having to find ways of escaping from it, relieved my anxiety greatly. I felt calm, even relaxed. 
Figure 1: $\quad$ Sample Rochester Interaction Record (RIR) Diary Record Sheet and Critical Incident Instructions*

* Note that the actual record sheets allowed more space for qualitative descriptions.

\section{DIARY RECORD SHEET}

Date. Time. am/pm Length of time of incident approx. minutes

No of people involved............Females/..........Males

\section{Where the incident took place:}

Nature of your interpersonal relationship with the person(s) involved (please circle)

Work relationship only/friends at work/friends outside of work/partner/family member/other please specify

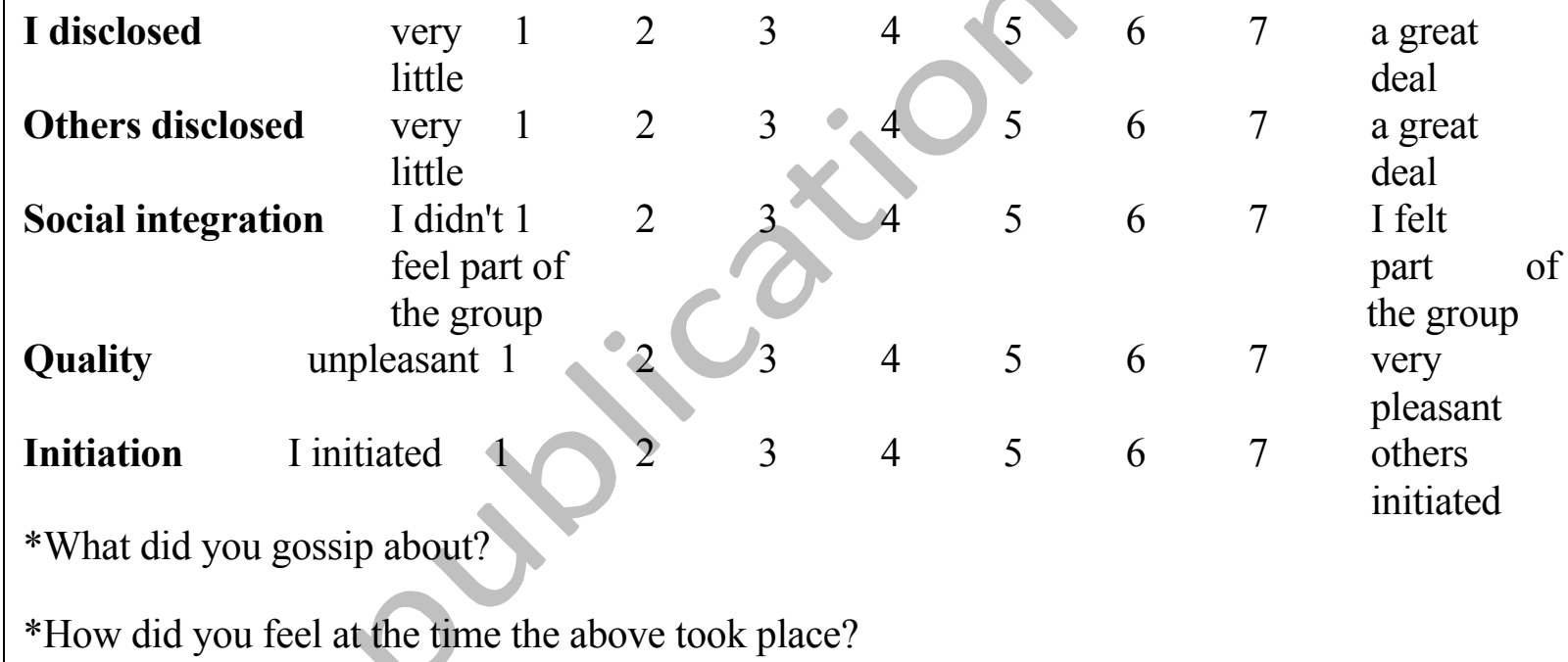

\section{A CRITICAL INCIDENT}

*Please describe in your own words details of one incident of work related gossip which occurred during the 2 weeks indicating:

1. Why you chose this particular incident

2. How you felt at the time

3. Where, when and who was involved (do not give names, if necessary use pseudonyms)

4. The nature of the gossip (again do not give names or inappropriate detail)

5. Any organizational factors which contributed to the occurrence of this particular incident

Please note, for reasons of confidentiality and research purposes, I am interested in the individual and organizational factors within this incident, rather than the specific content of what was said. 
Figure 2: $\quad$ Framework for Combining and Integrating Qualitative and Quantitative Data

Adapted from Waddington (2005)

TEXTUAL DATA

Styles of Analysis

Quasi-statistical: Researcher as analyst, identify units, sort into categories, describe/interpret using descriptive statistics and verify

\section{Levels of Analysis}

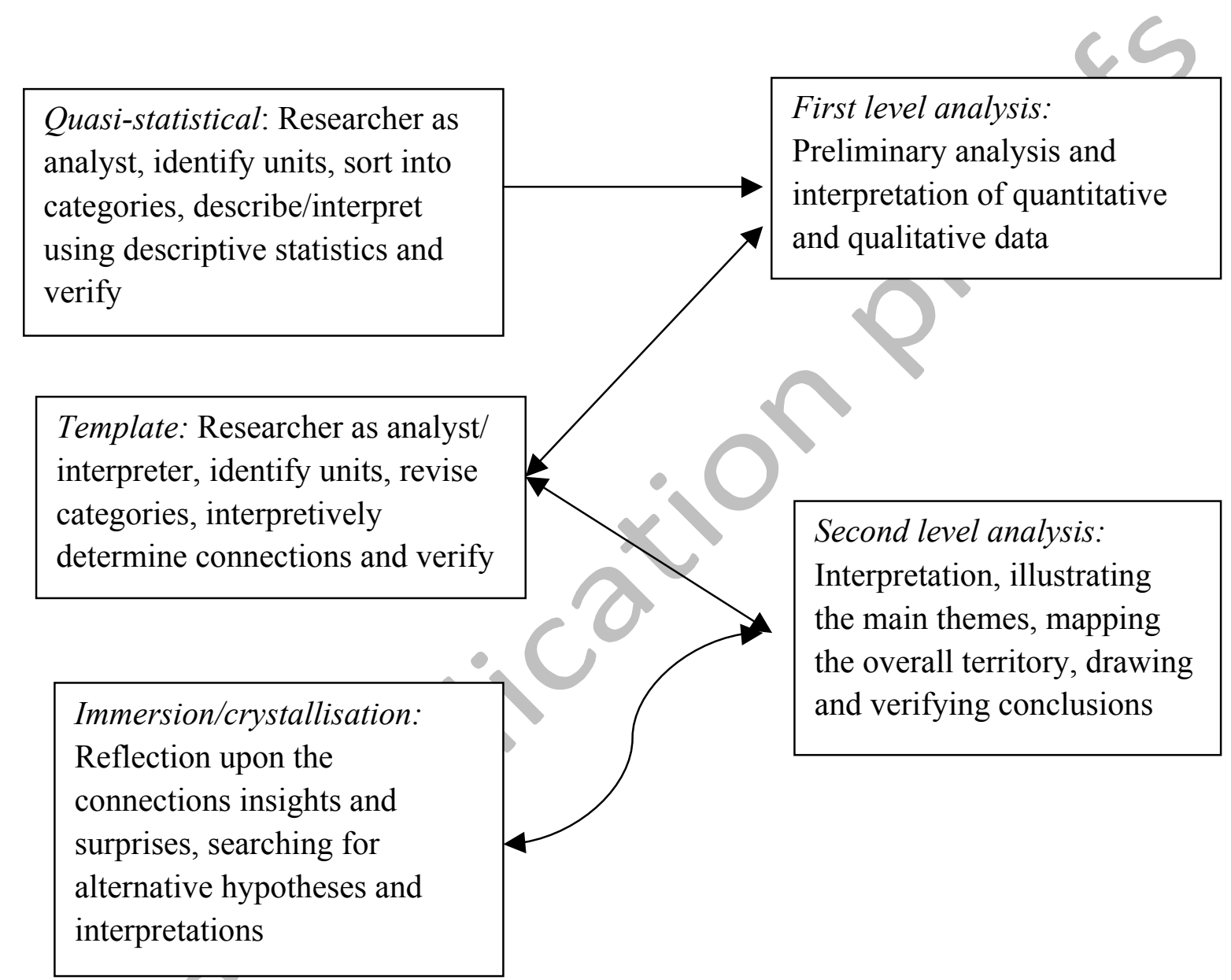


Waddington, K. (2013) 'Using qualitative diary research to understand emotion at work'. Chapter 10 in A. B. Bakker and K. Daniels (eds) A Day in the Life of a Happy Worker. Hove: Psychology Press.

Figure 3: $\quad$ Extract from diary study coding template

1 EMOTIONS EXPRESSED IN GOSSIP

1 Concern

$1 \quad$ Feeling concern about others

2 Caring about others

1 Concern for self

3 Frustration

1 Anger towards others

2 Irritation

4 Annoyance

$\begin{array}{ll}1 & \text { With self } \\ 2 & \text { With others }\end{array}$

1 Unprofessional behaviour

2 EMOTIONAL OUTCOMES OF GOSSIPING

1 Concern

1 Feeling concerned for others

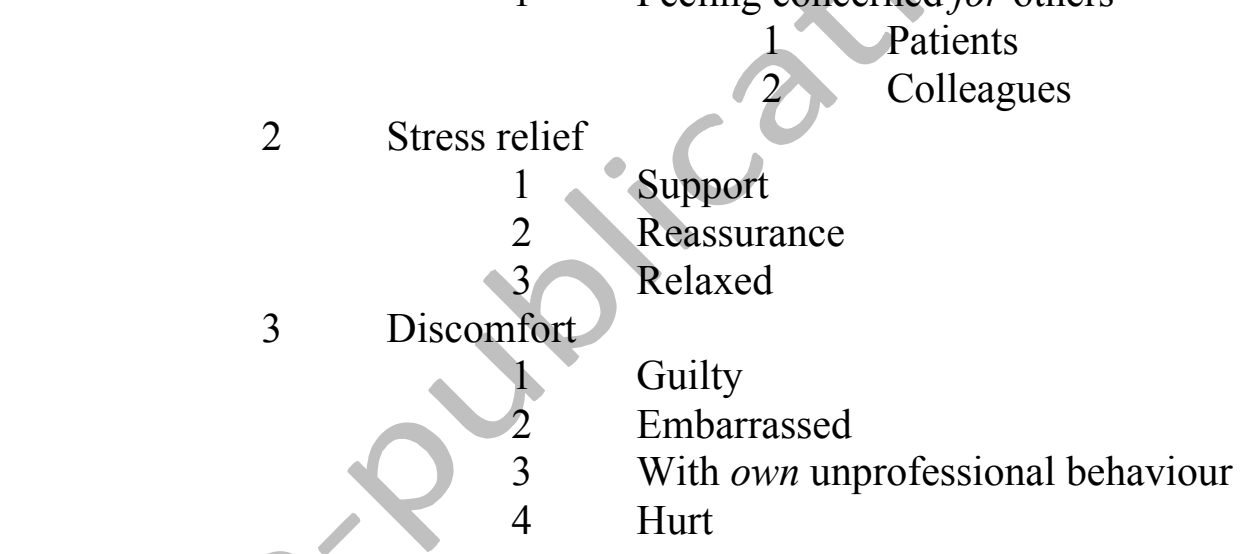

